\title{
Comparison of allogeneic stem cell transplant conditioning regimens in AML, MDS and CLL
}

\author{
Michele N West* \\ Department of Internal Medicine, Medical University of the Americas, USA
}

\begin{abstract}
Objective: The purpose of this hypothesis-driven review was to compare the prognostic outcomes of busulfan/cyclophosphamide combination therapy versus total bone irradiation in patients with acute myeloid leukemia.

Methods: A systematic search for randomized control trials, observational studies, meta-analyses, comparative studies, and systematic reviews comparing busulfan/ cyclophosphamide versus total bone irradiation conditioning regimens for allograft stem cell transplantation in patients with acute myeloid leukemia was performed using the following databases: PubMed, Medline, EBSCOhost, DynaMed, Google Scholar, and Cochrane Library. Studies were assessed for inclusion/exclusion criteria and methodological quality.

Results: A total of 9 studies were selected, pooling 15,004 HLA-matched participants of all ages with acute myeloid leukemia; this included 8,483 participants who received a total bone irradiation regimen and 6,521 who received a busulfan/cyclophosphamide regimen. Based on forest plot analysis, bubble-scatter plot analysis, Cohen's d test, and an unpaired t-test (for effect size), no statistically significant difference was found between the use of total bone irradiation and busulfan/ cyclophosphamide conditioning regimens on increased overall survival and disease-free survival in patients with acute myeloid leukemia (effect size: 0.20 ; relative risk: 1.27; $95 \%$ confidence interval $0.80-2.01, \mathrm{p}=0.36$ ). Serious adverse effects of total bone irradiation and busulfan/cyclophosphamide combination therapy were: graft versus host disease, alopecia, interstitial pneumonia, and cataract.
\end{abstract}

Conclusion: A busulfan/cyclophosphamide allogeneic stem cell transplantation conditioning regimen does not ameliorate prognosis (overall survival, disease-free survival, graft vs. host, and relapse rate) compared to a total bone irradiation conditioning regimen in patients with acute myeloid leukemia. This conclusions invalidity is questioned based on limitations of studies and inclusivity of multiple leukemic conditions amongst a broad population.

\section{Introduction}

Acute myeloid leukemia (AML) is a hematological cancer, characterized by a series of leukemo-oncogenic mutations that result in over-proliferation and accumulation of immature myeloid cells in the bone marrow [1]. This increase in proliferation causes thrombocytopenia, anemia, and ultimately bone marrow failure. Genome sequencing has confirmed that AML is associated with over 40 mutations, with the most common, FLT3 and IDH1/IDH2, being two-hit hypothesis mutations. Further common mutations include reciprocal balanced chromosomal rearrangements $(\mathrm{t}(8: 21))$ and $(\mathrm{t}$ (15:17)), which result in abnormal fusion of the retinoic receptor, interfering with granulocyte maturation and differentiation [2]. Other mutations, such as hyper-methylation of p15/INK4b, have also been implicated in the progression of AML, as have complete chromosomal deletions, such as $-3,-7,-5$ or -5 qdel. Children with genetic disorders like Klinefelter syndrome, Fanconi anemia, Li Fraumeni syndrome, and Down syndrome are also at risk of developing AML. These genetic modalities have been used in the diagnosis and risk classification for increased-years of life [3].

Molecular techniques and instrumentation have increased comprehension of AML disease processes, and yet it has one of the worst prognoses and lowest survival rates of all hematological neoplasms. According to the American Cancer Society, AML has a bimodal distribution of incidence of 4.3 per 100,000 individuals $<15$ years of age, with a peak incidence in children of 4 years old. AML accounts for $76 \%$ of common childhood leukemias. Approximately
$43 \%$ of adults, mostly men, with AML are $>65$ years old, and in this population, the disease has an incidence of 12.2 per 100,000. The ageadjusted incidence rate for AML in the United States was approximately 3.4 per 100,000 from 1973-2003,3 but, as of 2014, this has increased to 15 per 100,000 persons [4]. The reason for the increased age-adjusted incidence is unknown; however, it is speculated that it is associated with an increase in life expectancy or increased diagnosis of the disease in older populations. The correlation between age and increased disease incidence also predicts a poor prognosis in elderly patients, who are most commonly diagnosed with therapy-related AML. Therapy-related AML results from caustic chemical exposure, in addition to secondary cancer from alkylating chemotherapeutic drugs and topoisomerase inhibitors [4].

Studies have shown that the cytogenetics of AML are associated with survival rates and disease prognosis. True de novo mutations are commonly found in patients 65 years of age and older. Children, however, are more commonly found to have the reciprocal translocations $\mathrm{t}(2,11), \mathrm{t}(9,11),+21$, which are associated with a good prognosis based on performance status and response to treatment.

${ }^{\star}$ Correspondence to: Michele N. West, Department of Internal Medicine, Medical University of the Americas, USA, E-mail: m.west@mua.edu

Key words: acute myeloid leukemia; prognosis; conditioning; irradiation; transplantation

Received: May 03, 2018; Accepted: May 14, 2018; Published: May 17, 2018 
AML in children with trisomy 21 has the best prognosis and response to treatment. Children are also better candidates for chemotherapeutic agents and cytotoxic therapies, which impacts upon their overall survival (OS) rates. Studies have shown that patients with the $t(15: 17)$ reciprocal balanced translocation who receive all-trans retinoic acid (ATRA) induction therapy had a $71 \%$ survival rate, with a 3 -year OS rate of $50 \%$. Furthermore, studies have shown that the combination of ATRA with cytotoxic therapies has led to favorable survival outcomes [2]. As previously mentioned, the elderly population, or patients with true de novo mutations, cannot tolerate induction of cytotoxic treatments and have difficulties achieving remission. However, AML requires treatment because it is uniformly fatal, making definitive treatment availabilities most important both prognostically and clinically.

Historically, cytotoxic drugs, such as daunorubicin and cytarabine, were primarily used for treatment of AML. Studies showed that daunorubicin administered at double the standard dose increased the OS and complete remission of patients with AML under 60 years old. Daunorubicin treatment resulted in a $40 \%$ increase in the 5 -year survival rate when administered in combination with idarubicin. In 1994, cytarabine became the drug of choice for AML treatment. Studies showed that with continuous daily higher dose regimens, cytarabine increased the complete remission rate by $44 \%$ in AML patients aged 61 years and younger. In contrast, an older population of patients aged over 65 was intolerable to this induction treatment. Cytarabine at lower doses showed an increase in the overall survival, OS of patients with more than $30 \%$ blasts in the bone marrow [2]. More definitive treatment regimens are favored for better health outcomes.

In the late 1970s, scientists discovered the use of allogeneic stem cell transplantation in the treatment of hematopoietic blood cancer. Several meta-analysis studies have shown that stem cell transplantation significantly increased overall survival, OS and relapse-free survival, including in patients with true de novo mutations and poor-risk AML. Stem cell transplantation combined with chemotherapy reduced the percentage of abnormal cells in the bone marrow, in addition to increasing overall survival, OS. Patients who received stem cell transplantation combined with chemotherapy had a $65 \%$ reduction in mortality compared to those who only received chemotherapy [5].

Allogeneic stem cell transplantation for leukemia patients requires conditioning of the bone marrow. Long-term follow-up of patients who received stem cell transplantation conditioning using total bone irradiation (TBI) had secondary side effects, such as cardiac, endocrine, and neuroendocrine abnormalities, as well as impaired growth. A higher incidence of secondary leukemias occurred in almost $50 \%$ of cases [3]. Currently, cyclophosphamide and busulfan are the most commonly used chemotherapeutic drugs in an allogeneic stem cell transplant regimen. A review of comparative randomized studies found a clinically insignificant $10 \%$ lower OS with cyclophosphamide combined with busulfan in patients with AML. These patients also experienced complications, including hair loss and cataracts [6].

The objective of this review is to interosculate multiple studies conducted on comparative conditioning regimens in allogeneic stem cell transplantation for AML patients. This review will address whether irradiation of the bone marrow or combination chemotherapeutic agents, has the greatest effect on the prognosis of patients with AML. Based on a review of previous studies, it is hypothesized that combination therapy of cyclophosphamide and busulfan will lead to a better prognosis in comparison to TBI in patients with Acute Myeloid
Leukemia. The null hypothesis states that there is no significant difference between cyclophosphamide combined with busulfan versus TBI in the prognosis of patients with AML.

\section{Methods}

\section{Search Strategy and Inclusion/Exclusion Criteria}

The databases used in the search for meta-analyses, systematic reviews, randomized controlled trials, and retrospective and prospective cohort studies were as follows: PubMed, Medline, EBSCOhost, DynaMed, Google Scholar, and Cochrane. A PICO search was conducted using the following keywords or Mesh terms; (((acute myeloid leukemia [Mesh terms]) AND cyclophosphamide busulfan [Mesh terms]) AND total bone irradiation [Mesh terms]) AND prognosis [Mesh terms]. Similar articles were also selected to broaden the search outcomes. The criteria for inclusion were as follows: observational studies, systematic reviews, randomized control trials, and meta-analyses that focused on both younger and older human patients from birth to 95 years of age who were diagnosed with a hematological cancer, with an emphasis on acute myeloid leukemia. The studies must have been conducted within the last 10 years, and involved 2 comparative treatment groups. Finally, the full text and abstract had to be available for the study to be included. Included studies were those in which additional cytotoxic chemotherapeutic drugs in combination with cyclophosphamide and busulfan were considered. Excluded studies were those that did not include all keywords within the title and abstract, were conducted before 2006, were performed on animals, or had a title that was not relevant to the research question. Studies must include the following: systematic review, randomized control trial, meta-analysis, and observational study, to reduce the risk of bias. Prognostic outcomes were overall survival (OS), relapse rate, graft versus host, and disease-free survival (DFS). The study selection comprised of a thorough review of all abstracts of the proposed included studies. The full texts of the studies were obtained and critiqued with the applied inclusion criteria for eligibility for data analysis.

\section{Description of Studies}

Using the PICO and Mesh terms in the databases, 438 articles were identified. The filters and customization selection of articles published within the last 10 years resulted in 73 articles. Further customization and filters (randomized clinical trials, systematic reviews, and observational studies performed in adults under the age of 95 years and children under 18) were applied, resulting in 27 articles. Review of the abstracts, reading the full text, and excluding those with irrelevant titles resulted in 9 remaining articles [Figure 1]. These 9 articles met the inclusion criteria and are included within this hypothesis-driven review.

In the 6 retrospective studies, 2 prospective studies, and 1 observational study meeting the inclusion criteria, the number of participants totaled 15,004 . The studies were conducted in the following countries: Germany, Italy, Canada, Australia, New Zealand, France, India, Israel, and the United States. Appendix Table 1 describes how the data was synthesized based on location of the study, outcome, study population, study design, and interventions. The methodological quality of each study will be discussed later in this review. Due to the low number of recent studies and limited access to broad array of databases, population included were both children and adults, in addition to myelodysplatic syndromes, including ALL and MDS, but not limited to AML. 
Table 1. Evidence table for synthesizing data.

\begin{tabular}{|c|c|c|c|c|c|c|}
\hline $\begin{array}{l}\text { First Author, Date of } \\
\text { Publication }\end{array}$ & Location of Study & Study Design & $\begin{array}{l}\text { Level of } \\
\text { Evidence }\end{array}$ & Study Population & Exposure & Outcomes/ Results \\
\hline Copelan EA [8] & United States & Observational Study & 3 & $\begin{array}{l}\text { AML patients receiving } \\
\text { allograft bone marrow } \\
\text { transplants from siblings }\end{array}$ & $\begin{array}{l}\text { Busulfan and } \\
\text { cyclophosphamide } v s . \\
\text { TBI }\end{array}$ & $\begin{array}{l}\text { In combination with } \\
\text { Cyclophosphamide, IV Busulfan is } \\
\text { associated with superior outcomes } \\
\text { compared with TBI in patients with } \\
\text { AML in the first CR. }\end{array}$ \\
\hline Gupta T [10] & India & $\begin{array}{l}\text { Non-Randomized Control } \\
\text { Trial, Meta-Analysis, and } \\
\text { RCT }\end{array}$ & 2 & $\begin{array}{l}\text { Leukemia patients } \\
\text { conditioned with } \\
\text { either TBI or busulfan } \\
\text { combined with } \\
\text { cyclophosphamide. }\end{array}$ & $\begin{array}{l}\text { TBI vs. busulfan } \\
\text { combined with } \\
\text { cyclophosphamide }\end{array}$ & $\begin{array}{l}\text { Although not overly superior, } \\
\text { the weight of evidence favors } \\
\text { cyclophosphamide/TBI over busulfan/ } \\
\text { cyclophosphamide as a first choice- } \\
\text { conditioning regimen in patients with } \\
\text { leukemia. }\end{array}$ \\
\hline Nagler A [11] & Israel & $\begin{array}{l}\text { Observation Retrospective } \\
\text { Study }\end{array}$ & 3 & $\begin{array}{l}\text { Leukemic adult patients } \\
\text { receiving allograft }\end{array}$ & $\begin{array}{l}\text { Busulfan combined } \\
\text { with cyclophosphamide } \\
\text { vs. cyclophosphamide } \\
\text { combined with TBI }\end{array}$ & $\begin{array}{l}\text { This retrospective study shows that } \\
\text { final outcomes after myeloablative } \\
\text { conditioning using IV busulfan/ } \\
\text { cyclophosphamide were not } \\
\text { statistically different from those after } \\
\text { cyclophosphamide/TBI. }\end{array}$ \\
\hline de Berranger E [9] & France & $\begin{array}{l}\text { Observational Retrospective } \\
\text { Study }\end{array}$ & 3 & $\begin{array}{l}\text { AML patients under the } \\
\text { age of } 18\end{array}$ & $\begin{array}{l}\text { TBI combined with } \\
\text { cyclophosphamide } v s \text {. } \\
\text { busulfan combined with } \\
\text { cyclophosphamide }\end{array}$ & $\begin{array}{l}\text { In total, a busulfan/cyclophosphamide } \\
200 \text { conditioning regimen gives a } \\
\text { better outcome compared with TBI/ } \\
\text { cyclophosphamide, irrespective of the } \\
\text { stem cell source and the donor type. }\end{array}$ \\
\hline Shi-Xia X [13] & $\begin{array}{l}\text { United States, } \\
\text { Europe, Canada, } \\
\text { Japan, \& China }\end{array}$ & $\begin{array}{l}\text { Meta-Analysis, } \\
\text { Observational Studies }\end{array}$ & 3 & $\begin{array}{l}\text { Conditioned leukemia } \\
\text { patients }\end{array}$ & $\begin{array}{l}\text { TBI combined with } \\
\text { cyclophosphamide } v s \text {. } \\
\text { busulfan combined with } \\
\text { cyclophosphamide }\end{array}$ & $\begin{array}{l}\text { Our meta-analysis confirmed that } \\
\text { different regimens and type of } \\
\text { leukemia may affect the complications } \\
\text { and outcome. An analysis of the } \\
\text { effects of other regimens needs to be } \\
\text { carried out with large sample and well- } \\
\text { designed clinical trials. }\end{array}$ \\
\hline Uberti JP [15] & United States & $\begin{array}{l}\text { Retrospective observational } \\
\text { studies }\end{array}$ & 3 & $\begin{array}{l}\text { Leukemic patients } \\
\text { receiving bone marrow } \\
\text { transplant }\end{array}$ & $\begin{array}{l}\text { TBI combined with } \\
\text { cyclophosphamide } v s \text {. } \\
\text { busulfan combined with } \\
\text { cyclophosphamide }\end{array}$ & $\begin{array}{l}\text { We conclude that standard-dose } \\
\text { busulfan/cyclophosphamide and high- } \\
\text { dose cyclophosphamide/TBI regimens } \\
\text { have equivalent efficacy profiles for } \\
\text { OS, DFS, TRM and risk of relapse in } \\
\text { patients undergoing T-replete URD } \\
\text { marrow transplantation for AML, } \\
\text { CML, and MDS. }\end{array}$ \\
\hline Bredeson C [7] & United States & Prospective Cohort Study & 3 & $\begin{array}{l}\text { Patients with myeloid } \\
\text { malignancies undergoing } \\
\text { allograft bone marrow } \\
\text { transplantation }\end{array}$ & IV busulfan vs. TBI & $\begin{array}{l}\text { Compared with TBI, IV busulfan } \\
\text { resulted in superior survival with no } \\
\text { increased risk for relapse or TRM. } \\
\text { These results support the use of } \\
\text { myeloablative IV busulfan } v \text { s. TBI- } \\
\text { based conditioning regimens for } \\
\text { treatment of myeloid malignancies. }\end{array}$ \\
\hline Sisler IY [14] & $\begin{array}{l}\text { United States, } \\
\text { Europe, Australia, } \\
\text { \& New Zealand }\end{array}$ & $\begin{array}{l}\text { Retrospective observational } \\
\text { Study }\end{array}$ & 3 & $\begin{array}{l}\text { Pediatric patients with } \\
\text { AML }\end{array}$ & TBI & $\begin{array}{l}\text { Our study provides no evidence of an } \\
\text { advantage to using TBI in children } \\
\text { with AML beyond CR1. A prospective, } \\
\text { randomized study is needed to confirm } \\
\text { these results. }\end{array}$ \\
\hline Oyekunle AA [12] & Germany & $\begin{array}{l}\text { Retrospective Observational } \\
\text { Study }\end{array}$ & 3 & $\begin{array}{l}\text { Patients with refractory } \\
\text { acute leukemia }\end{array}$ & $\begin{array}{l}\text { TBI, cyclophosphamide } \\
\text { combined with busulfan, } \\
\text { and etoposide, } \\
\text { Methotrexate, and } \\
\text { cyclosporine for } \\
\text { prophylaxis. }\end{array}$ & $\begin{array}{l}\text { We conclude that patients with } \\
\text { refractory leukemia can benefit from } \\
\text { allogeneic BMT, especially with } \leq \\
20 \% \text { bone marrow blasts. }\end{array}$ \\
\hline
\end{tabular}

Level 0: Preclinical Studies- including experiemental studies and animal studies models; Level 1: Randomized controlled studies; Level 2: Non-randomizd controlled traial- a prospective (pre-planned) study with a predetermined eligibility criteria and outcome measures; Level 3:Observational studies with controls- includes retrospective, case-control studies and cohort studies; Level 4: Observational studies, without controls- includes cohort studies without controls, case series without controls, case studies without controls.

\section{Outcome Measurements}

All 9 studies measured overall survival, OS and disease-free survival, DFS as prognostic outcomes for the use of chemotherapeutic drugs and irradiation. OS and DFS were measured within a minimum of a 2 -year period and a maximum of a 10 -year period. DFS and OS are defined as the period in which a patient is alive without relapse, and the period in which they are still alive post-treatment, respectively. Further analysis of OS included neutrophil and platelet engraftment, which was measured within a 21-day interval post-treatment. All studies defined successful engraftment as 3 consecutive days with a neutrophil count of $500-1000 / \mu \mathrm{L}$ and a platelet count of $20 \times 10^{9} / \mathrm{L}$ using chimerism analysis. An engraftment regimen with Sargramostim treatment was only performed in 2 studies. Graft versus host disease (GVHD) was a secondary prognostic factor calculated into the relative risk of OS and DFS. GVHD was monitored acutely and chronically; symptoms included pneumonitis, generalized rash, and liver and renal failure. Conditioning to prevent GVHD included anti-thymocyte globulin/ alemtuzumab, mycophenolate, cyclosporine A, and methotrexate. Other secondary prognostic factors that influenced OS and DFS were 


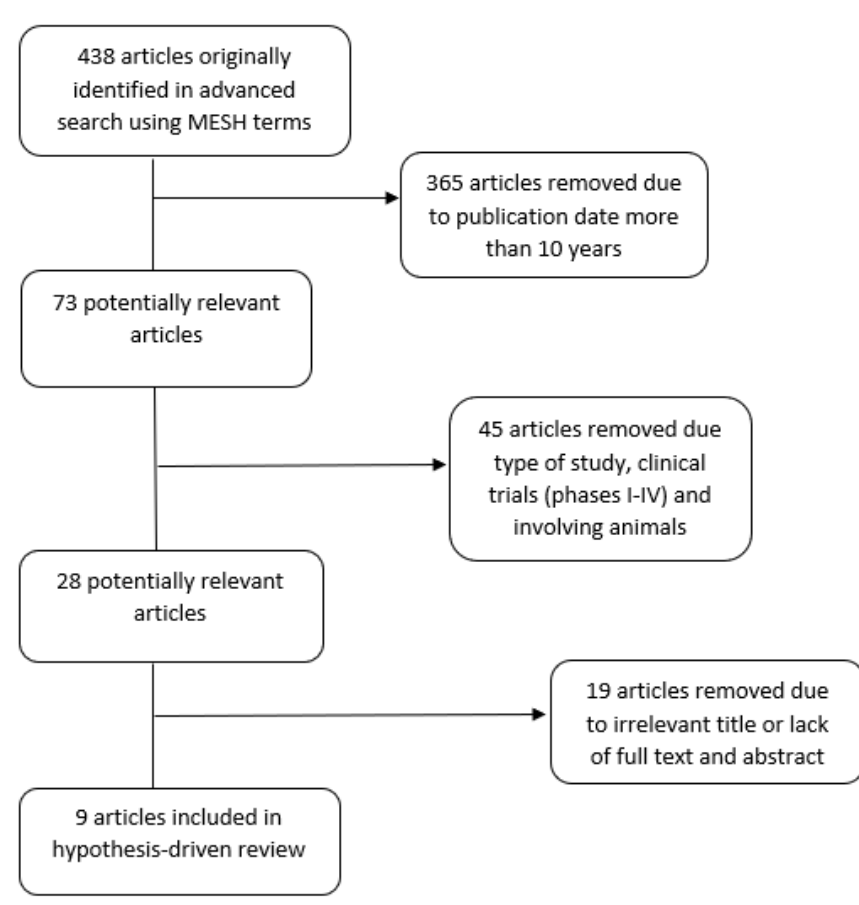

Figure 1. Flowchart for identification of studies included in the hypothesis-driven review of observational studies, systematic reviews, and meta-analyses comparing a TBI regimen versus a cyclophosphamide regimen in patients with AML.

relapse or leukemia-free survival, infections, toxicity-induced illnesses, and ultimately, transplant-associated mortality. Overall survival, OS and disease-free survival, DFS prognostic variable probabilities were calculated using the Kaplan-Meier method. The secondary prognostic variables were calculated using the cumulative incidence. SPSS (SPSS Inc., Chicago, USA) and SAS (Statistical Analysis System, Cary, USA) were common statistical programs used in the studies.

\section{Methodological Quality of Included Studies}

The quality of each study was assessed using randomization, blinding, informed consent, and establishment of stringent inclusion and exclusion criteria. These criteria were based on HLA karyotypes and "poor-risk" and "good-risk" WHO-classified cytogenetics, contingent upon specific chromosomal translocations and gene deletions. All studies described inclusion and exclusion criteria, with the inclusion criteria of 5 studies based on HLA karyotypes (HLA-A, -B, -C and DRB1) and cytogenetics (inv 16, t (8;21), t (9;11), t (6;9), -7, -5/5q-, $3 q)$. The median age of each participant was also considered. HLA karyotypes and cytogenetics were confirmed using Fluorescent in situ Hybridization (FISH), flow cytometry, and Polymerase Chain Reaction (PCR). All participants receiving a stem cell transplant underwent HLA-donor matching. Five studies conducted randomization of participants. All studies obtained informed consent, with the required IRB (Institutional Review Board) approval. All studies obtained patient data from a registry or transplantation database, as well as retrospective studies obtained from research databases. One study conducted a double-blinded study, removing identifiers from patient samples. Four of the nine studies measured quality of life and daily living activities of patients using the Lansky/Karnofsky score; a score greater than or equal to 90 defines a good quality of life. All studies listed the dosing and interval of each intervention. Allocation of treatment was blinded in 1 study. Allocation of treatment was randomized in 1 study; however, the classification of such treatment allocations was not clearly defined in all studies. Treatment dosing (standard dose and high dose) was listed in all studies, along with the route of administration. In most studies, busulfan is administered both orally and intravenously (IV). However, oral administration was not rigorously recorded; thus, IV busulfan will only be considered for this review. The median follow-up time was defined in all studies. Table 2 lists the participant criteria and interventions of each study.

\section{Results}

\section{Overall Survival and Disease-Free Survival}

Analysis of the pooled statistical outcomes of each study was performed using Microsoft Excel 2016. All participants were divided into 2 groups according to receipt of total body irradiation (TBI) and busulfan/cyclophosphamide therapy, and tabulated for each study with the correlated relative risk and upper and lower confidence intervals [Table 3]. The data were analyzed and results constructed using a forest scatter plot, calculated using Cohen's d and unpaired t-test [Figure 2]. The forest analysis compared the effect of TBI versus busulfan/ cyclophosphamide conditioning regimens on overall survival, OS and disease-free survival, DFS across all 15,004 participants; the analysis showed no statistically significant difference (effect size, ES $=0.20$; relative risk, RR: 1.27 ; $95 \%$ confidence interval $0.80-2.01, \mathrm{p}=0.36$ ). A Kaplan-Meier measurement of survival between 7 studies $(n=12,622$ participants) using a bubble scatter plot to compare the 2, 3, 4, and 5 -year interval progression (x-axis) and OS probability (y-axis) was constructed [Figure 3]. In some studies, OS increased from 2 to 5 years post-treatment for the busulfan/cyclophosphamide conditioning regimen, while for the TBI conditioning regimen, the OS decreased from 2 to 5 years' post-treatment. The overlapping of OS probability outcomes of the 7 studies showed no significant difference over the course of 2 to 5 years with either conditioning regimen. HLAmatching is an important prognostic factor in OS9 with the use of busulfan/cyclophosphamide combination therapy compared to the TBI conditioning regimen. Multivariate analysis in 6 studies concluded that there was no significant difference between TBI and busulfan/ cyclophosphamide regimens, even in patients with good and poor cytogenetics. Two studies concluded statistical significance in OS and DFS using the TBI regimen, with 1 study only finding significance in patients with $20 \%$ or more blasts in the bone marrow.

\section{Graft versus Host Disease \& Engraftment}

Graft vs Host Disease is the most common cause of transplantrelated mortality. GVHD was measured both acutely and chronically, at intervals from a few weeks up to 1 year, and was graded from 1 to 4 , based on the level of severity. Multivariate analysis of 5 studies showed no differences in GVHD between TBI and busulfan/cyclophosphamide regimens, although the probability of survival was slightly lower for TBI regimens in patients who received higher doses of radiation. High dose TBI increased the incidence of acute GVHD and leukemia relapse. Four studies, however, showed significance between TBI and busulfan/cyclophosphamide conditioning regimens, with a decreased incidence of GVHD depending on age, route of administration, and HLA-matching. Older patients were at higher risk of a GVHD. Overall, patients responded better to IV busulfan/cyclophosphamide regimens in conjunction with improved HLA-donor matching.

Engraftment was measured by neutrophil and platelet recovery at a median of 28 days (range 14-40 days). Three studies showed that an IV busulfan/cyclophosphamide regimen increased both neutrophil and platelet engraftment to almost $99 \%$ compared to the TBI regimen. A standard dose (100-1260 cGY) TBI regimen was shown by 2 studies 
Table 2. Methodological quality assessment for included studies in hypothesis-driven review of comparing a TBI regimen versus busulfan/cyclophosphamide combination in patients with Acute Myeloid Leukemia.

\begin{tabular}{|c|c|c|}
\hline Study & Participants & Intervention \\
\hline Bredeson [7] United States & $\begin{array}{l}\mathrm{N}=1483 \text {, age } \leq 60 \text { years, HLA-matched, diagnosis AML, } \\
\text { MDS, allogeneic transplant }\end{array}$ & $\begin{array}{l}\text { IV-BU }(>9 \mathrm{mg} / \mathrm{kg}) \text { plus CY }(\geq 60 \mathrm{mg} / \mathrm{kg}) \text { or FLU }(\geq 80 \\
\left.\mathrm{mg} / \mathrm{m}^{2}\right) \text { or TBI } \geq 500 \mathrm{cGy} \text { single fraction or } \geq 800 \mathrm{cGy} \\
\text { fractioned) plus CY }(\geq 60 \mathrm{mg} / \mathrm{kg}) \text { or etoposide }(\geq 30 \mathrm{mg} / \mathrm{kg})\end{array}$ \\
\hline Copelan [8] United States & $\begin{array}{l}\mathrm{N}=1230 \text {, age }<40 \text { years, median age } 35 \text { years, HLA-matched, } \\
\text { diagnosis AML, allogeneic transplant }\end{array}$ & $\begin{array}{l}\text { TBI/cyclo unfractionated dose } \geq 5.5 \mathrm{GY}, \text { fractioned } \geq 9 \mathrm{GY} \\
\text { or IV BUCY }(\geq 9 \mathrm{mg} / \mathrm{kg}) \text { w/o additional chemotherapeutic } \\
\text { agents }\end{array}$ \\
\hline de Berranger [9] France & $\begin{array}{l}\mathrm{N}=226 \text {, age }<18 \text { years, median age } 13 \text { years, HLA-matched, } \\
\text { allogeneic transplant, diagnosis AML CR } 1\end{array}$ & $\begin{array}{l}\text { TBI/cyclo } 1200 \text { cGy } 6 \text { fractions } 2 \text { consecutive days, BUCY } \\
16 \mathrm{mg} / \mathrm{kg} \text { oral or IV, split } 4 \text { x } 4 \text { consecutive days, } 50 \mathrm{mg} / \mathrm{kg} / \\
\text { day } 4 \text { additional days }(200 \mathrm{mg} / \mathrm{kg} \text { total })\end{array}$ \\
\hline Gupta, 2011 [10] India & $\mathrm{N}=6280$, age $<60$ years, diagnosis $\mathrm{AML}$, leukemias & $\begin{array}{l}\text { BUCY120 (120 mg/kg cyclophosphamide)/ BUCY200 (120 } \\
\mathrm{mg} / \mathrm{kg} \text { cyclophosphamide) CYTBI }\end{array}$ \\
\hline Nagler, 2013 [11] Israel & $\begin{array}{l}\mathrm{N}=1659 \text {, age }>18 \text { years, median age } 39 \text { years, HLA-matched, } \\
\text { diagnosis AML }\end{array}$ & $\begin{array}{l}\text { IV BUCY median dose } 12.8 \mathrm{mg} / \mathrm{kg} \text { (interquartile range), } \\
\text { 12.6-12.8; median TBI dose } 12 \mathrm{~Gy} \text { (range } 7.5-14.4 \text { ) }\end{array}$ \\
\hline Oyekunle, 2006 [12] Germany & $\begin{array}{l}\mathrm{N}=44, \text { age }<60 \text { years, median age } 28 \text { years, HLA-matched, } \\
\text { diagnosis AML }\end{array}$ & $\begin{array}{l}\text { Cyclophosphamide } 60 \mathrm{mg} / \mathrm{kg} / \mathrm{day} \text { IV on } 2 \text { consecutive days } \\
(120 \mathrm{mg} / \mathrm{kg} \text { total dose); etoposide } 30-45 \mathrm{mg} / \mathrm{kg} \text { IV; BU } 12- \\
16 \mathrm{mg} / \mathrm{kg} \text { p.o or IV equivalent ( } 1 \mathrm{mg} \mathrm{p} . \mathrm{o}=0.8 \mathrm{mg} \text { IV on } 4 \\
\text { consecutive days, TBI } 12-13.5 \text { Gy } 12 \text { fractionated } 3 \text { days }\end{array}$ \\
\hline $\begin{array}{l}\text { Shi-Xia, } 2010 \text { [13] United States, Canada, Europe, Japan, } \\
\text { \& China }\end{array}$ & $\begin{array}{l}\mathrm{N}=2338 \text {, age }<59 \text { years, diagnosis AML, matched or } \\
\text { mismatched HLA }\end{array}$ & $\begin{array}{l}\text { Total body irradiation was applied as a single dose of } 7.5 \text { to } \\
10 \text { Gy or in } 4 \text { to } 6 \text { fractions with a total dose of } 12 \text { to } 15 \mathrm{~Gy} \text {. } \\
\text { Busulfan was administered orally at } 16 \mathrm{mg} / \mathrm{kg} \text { for } 4 \text { days and } \\
\text { cyclophosphamide was administered at } 120 \mathrm{mg} / \mathrm{kg} \text {. }\end{array}$ \\
\hline $\begin{array}{l}\text { Sisler, } 2009 \text { [14] United States, Europe, Australia, \& New } \\
\text { Zealand }\end{array}$ & $\begin{array}{l}N=151 \text {, age } \leq 21 \text { years, median age } 9 \text { years, diagnosis AML } \\
\text { CR1-CR } 4\end{array}$ & $\begin{array}{l}\text { TBI or busulfan (IV and p.o.) combination, } \\
\text { cyclophosphamide, melphalan, or fludarabine; dosing not } \\
\text { specified }\end{array}$ \\
\hline Uberti, 2011 [15] United States & $\begin{array}{l}\mathrm{N}=1531 \text {, age }<60 \text { years, median age } 37 \text { years, diagnosis } \\
\text { AML, MDS, HLA matched }\end{array}$ & $\begin{array}{l}\text { BU } 16 \mathrm{mg} / \mathrm{kg} \mathrm{w} / \mathrm{CY} 120-200 \mathrm{mg} / \mathrm{kg} \text {, i.v. \& p.o.; TBI } \\
\text { standard dose (1000-1200 cGy) or high dose (1320-1500 } \\
\text { cGy) }\end{array}$ \\
\hline
\end{tabular}

Table 3. Characteristics of patients and 9 study outcomes comparing TBI and BUCY conditioning regimens.

\begin{tabular}{|c|c|c|c|c|c|c|c|c|}
\hline Study Author & $\begin{array}{c}\text { Number of } \\
\text { Participants }\end{array}$ & TBI Regimen & $\begin{array}{c}\text { Bus/Cyclo } \\
\text { Regimen }\end{array}$ & Relative Risk & CI lower & CI Higher & $95 \% \mathrm{CI}$ assumed & $\begin{array}{c}\text { Median Follow- } \\
\text { up }\end{array}$ \\
\hline Bredeson, et al. [7] & 1483 & 458 & 1025 & 0.82 & 0.68 & 0.98 & $\mathrm{P}=0.03$ & 24 months \\
\hline Copelan, et al. [8] & 1230 & 586 & 644 & 0.68 & 0.52 & 0.88 & $\mathrm{P}=0.003$ & 68 months \\
\hline de Derranger, et al. [9] & 226 & 84 & 142 & 1.8 & 1.1 & 2.8 & $\mathrm{P}=0.02$ & 59 months \\
\hline Gupta, et al. [10] & 6280 & 3938 & 2342 & 0.82 & 0.64 & 1.05 & $\mathrm{P}=0.12$ & 37 months \\
\hline Nagler, et al. [11] & 1659 & 864 & 795 & 0.97 & 0.79 & 1.18 & $\mathrm{P}=0.74$ & 33 months \\
\hline OyeKunle, et al. [12] & 44 & 19 & 25 & 2.44 & 1.13 & 5.25 & $\mathrm{P}=0.023$ & 25 months \\
\hline Shi-Xia, et al. 2010 [13] & 2338 & 1169 & 1169 & 1.49 & 1.01 & 2.2 & $\mathrm{P}=0.04$ & 84 months \\
\hline Sisler, et al. 2009 [14] & 151 & 90 & 61 & 1.42 & 0.76 & 2.64 & $\mathrm{P}=0.27$ & 32 months \\
\hline Uberti, et al. 2011 [15] & 1593 & 1275 & 318 & 1 & 0.58 & 1.13 & $\mathrm{P}=0.236$ & 97 months \\
\hline
\end{tabular}

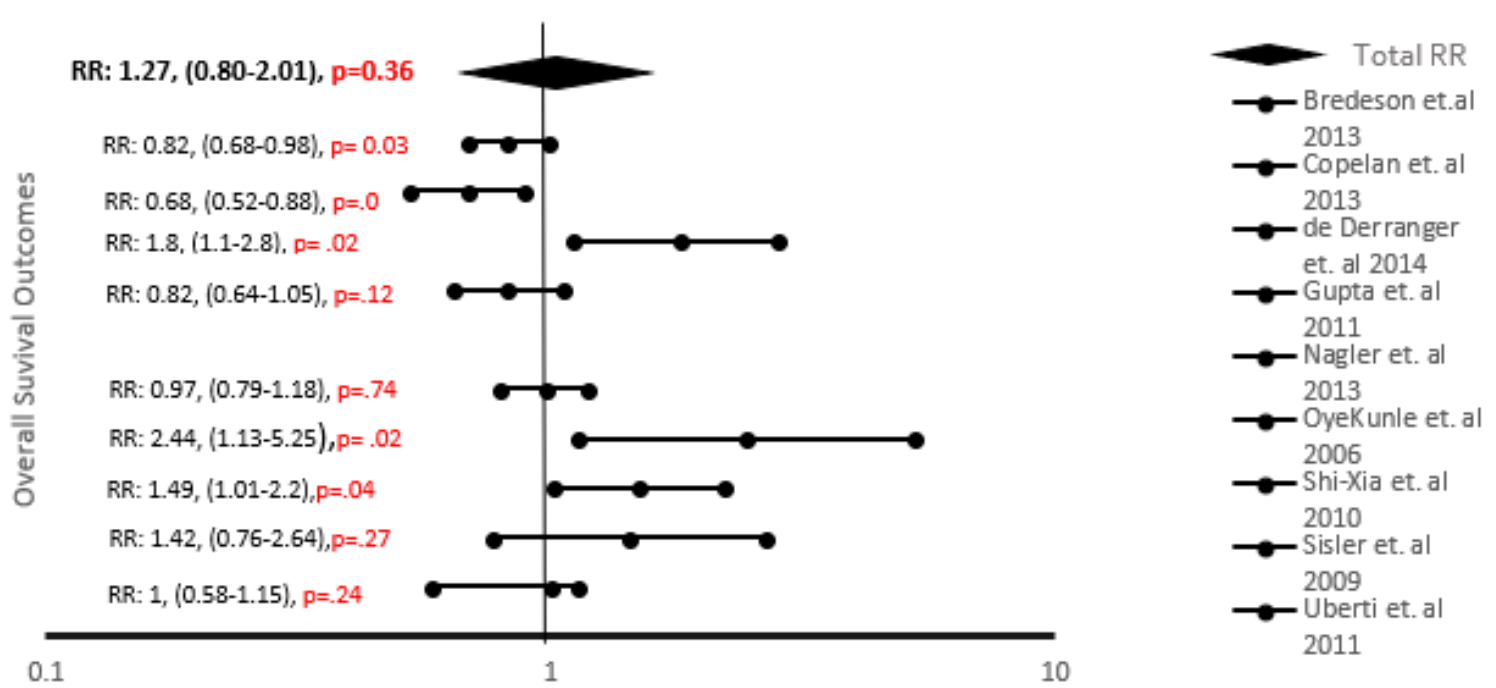

Favours TBICY vs Favours BUCY

Figure 2. Forest plot of results for comparing the overall survival and disease free-survival of TBI vs. busulfan/cyclophosphamide regimens in patients with Acute Myeloid Leukemia. 


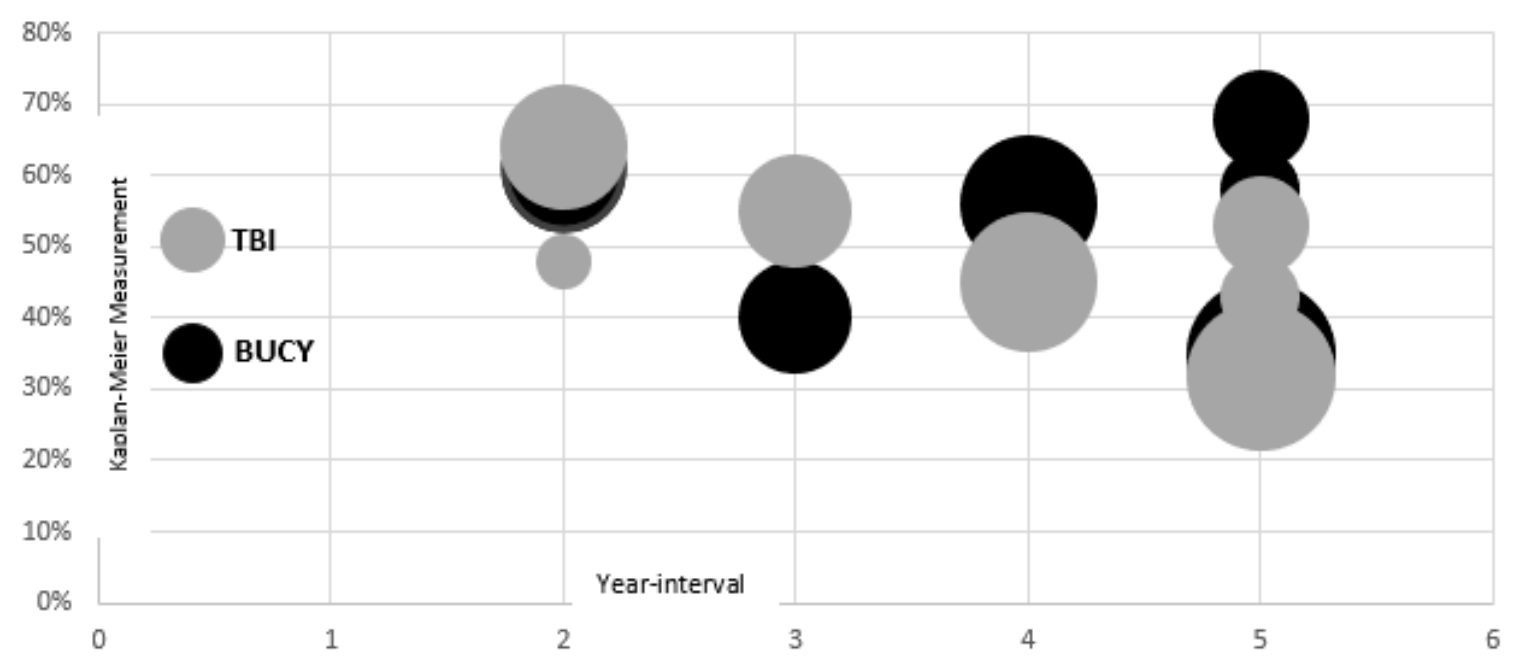

Figure 3. Bubble scatterplot including 7 studies, for comparing BUCY and TBI conditioning regimens in overall survival, OS progression from 2 to 5 year-intervals.

to have significant neutrophil and platelet engraftment outcomes compared to standard dose busulfan/cyclophosphamide regimens and high dose TBI regimens. Other studies did not find a significant difference between neutrophil and platelet engraftment in either regimen; however, all studies reported a lower incidence of relapse and graft failure with both conditioning regimens. Stringent HLA donor matching was associated with a lower relapse rate in engraftments.

\section{Other Prognostic Variables}

Using the Fine and Gray method for multivariate analysis, standard dose TBI conditioning was found to be associated with a lower cumulative incidence of transplant-related mortality compared to higher dose TBI and busulfan/cyclophosphamide regimens. One study reported a lower incidence of transplant-related mortality with a busulfan/cyclophosphamide regimen when proper HLA-donor matching was performed. As reported in 3 studies, no significant difference was noted in all conditioning regimens. Non-relapse mortality was associated with a standard dose TBI regimen when compared to an IV standard dose busulfan/cyclophosphamide regimen. There was a higher incidence of relapse (defined as more than $5 \%$ leukemic cells in the bone marrow) and leukemic cells detected outside the bone marrow with high dose TBI regimens as compared to IV administration of busulfan/cyclophosphamide. Mild side effects of alopecia and cataracts were reported from exposure to both regimens. Two of these studies demonstrated the comparison of TBI verses IV standard dose busulfan/cyclophosphamide regimen through measurement of a Lansky/Karnofsky performance score, of which a score of $\geq 90 \%$ concluded with the busulfan/cyclophosphamide conditioning regimens, with a low comorbidity index of 0 to 3 . In contrast, 1 study concluded that there was no significant difference in performance scores between the 2 conditioning regimens.

\section{Discussion}

With considerable improvements in the treatment modalities for leukemia, AML is no longer a diagnosis of shortened-life span for patients. Before the 1960s, the median survival time was approximately 2 months; since then, it has significantly increased and is now 1 to 2 years [2]. This increase has been attributed to the combination of allogeneic stem cell transplantation and chemotherapeutic agents. Although there has been an increase in the median survival time from the 1980s to the present day, the overall survival, OS has remained constant at approximately 1 to 2 years [2]. Thus, more studies are needed to examine the effective therapeutic regimens that increase the OS of patients with AML.

This study pooled 15,004 participants of all ages with AML; 8,483 participants underwent a TBI regimen and 6,521 participants received a busulfan/cyclophosphamide conditioning regimen for allograft stem cell transplantation. Using forest plot analysis with RR and ES for overall survival, OS and disease-free survival, DFS, this hypothesisdriven review concluded that there was no statistical significance between the use of busulfan/cyclophosphamide and TBI conditioning regimens for allograft stem cell transplantation in patients with AML. While some studies reported a slightly better response with IV busulfan compared to oral busulfan, multivariate analysis concluded that there was no significant difference between any of the conditioning regimens. Other complications of using either combination busulfan/ cyclophosphamide verses $\mathrm{TBI} /$ cyclophosphamide regimens include GVHD, alopecia, increased risk of relapse, and cataracts. The selection of immunosuppressive therapies to prevent GVHD varied between studies, and included anti-thymocyte globulin/alemtuzumab, methotrexate, and cyclosporine A. Improper immunosuppression therapies and HLA-matching increased the risk of chronic GVHD, which leads to sepsis and subsequent mortality in many patients. HLA-matching was concluded to be a crucial prognostic factor for OS. However, the degree of HLA complementation and donor type (related or unrelated donor) was not clearly specified. Neutrophil and platelet engraftment showed an $80-99 \%$ bone marrow improvement in all studies, as measured from 3 to 40 days post-treatment. There was no significant difference between TBI and busulfan/cyclophosphamide conditioning regimens on engraftment outcomes; thus, a busulfan/ cyclophosphamide conditioning regimen is not superior to a TBI conditioning regimen. Both regimens have comparable outcomes in terms of graft vs. hosts responses in patients with AML. Although the engraftment outcomes were positive, i.e., decreased rates of graft vs. host, it did not neither improve overall survival (OS) nor disease-free survival (DFS) prognoses. Performance score was not considered an integral prognostic factor, but more studies are needed to compare pre-transplantation and post-transplantation scores between both regimens and their effect on prognosis of AML.

Improved overall survival, OS for patients with both good risk and poor risk cytogenetic AML has been noted with the use of allogeneic 
stem cell transplantation [5]. Allogeneic stem cell transplantation requires myeloablative conditioning, which commonly uses TBI, but has recently combined irradiation with chemotherapeutic agents. Currently, there are no standardized dosing interventions, fraction doses, or modes of administration for these combinative conditioning regimens [16]. Additionally, there is also no standard allocation of how each conditioning regimen is administered to patients with AML [11]. Treatment responses post-transplantation are commonly measured using the percentage of blasts in the bone marrow. Patients with fewer than $20 \%$ blasts in the bone marrow show decreased graft-vs-host responses to combined chemotherapy and irradiation treatment [12].

Studies have shown varying outcomes based upon comorbidity, age, sex, and, most of all, cytogenetics. In an older population with comorbidities, the toxic side effects of higher doses of each regimen resulted in a higher incidence of mortality. Other studies also concluded that a high comorbidity index score of 3 was predictive of shorter survival in adult patients with AML [5]. Older patients were also more likely to have poor-risk cytogenetics $(-7,-5 / 5 q-, 3 q$ complete chromosomal deletions), associated with myelodysplastic syndrome (MDS)-related AML. Patients with good-risk cytogenetics (t (8:21, $\operatorname{inv}(16), t(15: 17),+21)$ responded better to both conditioning regimens with a lower incidence of mortality, although both cytogenetic types showed no difference in relapse and overall survival, OS, even at standard doses of each conditioning regimen. Furthermore, there are unclear specifications regarding the classification of cytogenetics as good-risk or poor-risk and its association with therapy allocation and response to treatment. It is also unclear whether these genetic deletions are associated with therapeutic responses. The NQO1 polymorphic variant has been associated with therapy-related cytogenetics [3].

Allocation of treatment can also be influenced by patient characteristics, such as insurance coverage and socioeconomic status. Studies have shown that white patients have better access to private and more expensive insurance compared to ethnic minority groups, resulting in differences in mortality outcomes. Regardless of either conditioning regimen, studies have shown that patients with private insurance had an overall survival, OS of 22 months compared with patients on Medicare who had an OS of 13 months [5]. Thus, mortality differences between ethnic groups are based on socioeconomics and access to quality insurance, rather than solely on cytogenetics. Conditioning treatments are expensive and have limited availability, meaning that only those with private insurance will benefit [5]. Medicare patients are 65 years and older, which may explain why this age group has poorer outcomes. Men in this age group have a higher incidence of AML than women, who have a $10 \%$ lower risk of mortality.

The sole use of a TBI conditioning regimen in allogeneic stem cell transplantation has been associated with an increased risk of acute and chronic GVHD and an increased leukemia relapse rate, in addition to growth abnormalities and endocrine dysfunction [16]. However, multivariate analysis concluded that there is no significant difference between TBI and busulfan/cyclophosphamide conditioning regimens [14]. Both regimens have been associated with toxic effects such as interstitial pneumonitis, fungal and bacterial infections, mucositis, and sinusoidal obstructive syndrome. Oral busulfan combined with cyclophosphamide is a cheaper formulation than IV busulfan combined with cyclophosphamide. However, busulfan and cyclophosphamide require hepatic metabolism, which produces hepatic toxic metabolites, depletes glutathione, and increases the incidence of hepatic injury and veno-occlusive disease (VOD) [17]. Oral busulfan has a narrow therapeutic index and is associated with earlier onset of toxic side effects, including interstitial pneumonitis and hemorrhagic cystitis. IV busulfan is easily formulated to the patients' pharmacokinetics and decreases the incidence of early onset toxicities, meaning that IV busulfan is a better choice for conditioning regimens.

\section{Limitations}

Study limitations include the limited number of databases and reliable data available for access, which leads to the potential exclusion of studies and articles; this may in turn influence the validity of the outcomes and introduce potential bias. This study only includes 9 studies, one of which was published 10 years ago. There were limited newly published data available for further analysis, which may have influenced the validity of the results, and increased bias and random error in the outcomes. In addition, the population included in the study were both children and adults, of which stem cell transplantation biology greatly differ. Furthermore, this analysis included various types of myelodysplasias and leukemias, which have different etiologies and mutations. Administration and treatment regimen also differed amongst each study. Of all these differences and small variations within each study, these limitations place invalidity and unreliability of the overall statistical outcomes.

\section{Conclusion}

Currently, there are no definitive conclusions regarding the effect of allogeneic stem cell transplantation conditioning regimens on prognostic outcomes in patients with various forms of leukemia and MDS. More studies and clinical research are needed to determine guidelines for therapeutic dosing and intervals, engraftment, and immunosuppressive therapy. Furthermore, allocation of treatment is dependent upon the patients' individual characteristics; these include, but are not limited to comorbid conditions and indices, cytogenetic risk classification using FISH analysis of chromosomal translocations and deletions, pre-transplantation percentage of blasts, and patient demographics (e.g. age and insurance coverage). Since HLA-matching is a significant prognostic factor for overall survival, OS, expansion of HLA typing to include HLA-DRI, DP, and DQ, along with HLA-A, B, and $\mathrm{C}$, can be considered to increase stringency in donor matching; this is particularly important for patients for whom non-relative donor matching must be considered. Immunosuppression therapy is an integral part of the pre-transplantation conditioning regimen. More studies are needed to examine the effect of immunosuppression therapies used in combination with a conditioning regimen on decreasing the incidence of chronic GVHD. This in turn will increase the OS and disease-free survival, DFS of patients with AML. Overall, more current studies, which include stringency in measuring OS and DFS, in conjunction with, stringent cytogenetic categorization and allocation of chemotherapeutic/radiation treatments are required to establish validity in efficacy of these differing treatment methods.

\section{References}

1. Kumar V, Abbas AK, Aster JC (2015) Robbins \& Cotran: Pathological Basis of Disease. ( $9^{\text {th }}$ Edn) Professional Edition, Philadelphia, P.A.

2. Freireich EJ, Wiernik PH, Steensma DP (2014) The Leukemia: A Half-Century Discovery. J Clin Oncol 32: 1-7. [Crossref]

3. Deschler B, Lubbert M (2006) Acute Myeloid Leukemia: Epidemiology and Etiology. Cancer 107: 2099-2107. [Crossref]

4. Howard J (2014) Myeloid Malignancies: WTC Health Program \& Monitoring Treatment.

5. Master S, Mansour R, Devarakonda SS, Shi Z, Mills G, et al. (2016) Predictors of Survival in Acute Myeloid Leukemia by Treatment Modality. Anticancer Res 36: 1719-1728. 
6. Socié G, Clift RA, Blaise D, Devergie A, Ringden O, et al. (2001) Busulfan plus cyclophosphamide compared to total-body irradiation plus cyclophosphamide before marrow transplantation for myeloid leukemia: long-term follow up of 4 randomized studies. Blood 98: 3569-3573. [Crossref]

7. Bredeson C, LeRademacher J, Kato K, Dipersio JF, Agura E, et al. (2013) Prospective cohort study comparing intravenous busulfan to total body irradiation in hematopoietic cell transplantation. Blood 122: 3871-3878. [Crossref]

8. Copelan EA, Hamilton BK, Avalos B, Ahn KW, Bolwell BJ, et al. (2013) Better leukemia-free and OS in AML in first remission following cyclophosphamide in combination with busulfan compared with TBI. Blood 122: 3863-3870. [Crossref]

9. de Berranger E, Cousien A, Petit A, Peffault de Latour R, Galambrun C, et al. (2014) Impact on long-term OS of conditioning regimen in allogeneic BMT for children with AML in first CR:TBI+CY versus BU+CY: a report from the Société Française de Greffe de Moelle et de Thérapie Cellulaire. Bone Marrow Transplant 49: 382-388. [Crossref]

10. Gupta, T, Kannan, S, Dantkale V, Laskar S (2013) Cyclophosphamide plus total body irradiation compared with busulfan plus cyclophosphamide as a conditioning regimen prior to hematopoietic stem cell transplantation in patients with leukemia: a systematic review and meta-analysis. Hemat Oncol Stem Cell Ther 4:17-29. [Crossref]

11. Nagler A, Rocha V, Labopin M, Unal A, Ben Othman T, et al. (2013) Allogeneic hematopoietic stem-cell transplantation for acute myeloid leukemia in remission: comparison of intravenous busulfan plus cyclophosphamide $(\mathrm{Cy})$ versus total-body irradiation plus $\mathrm{Cy}$ as conditioning regimen--a report from the acute leukemia working party of the European group for blood and marrow transplantation. J Clin Oncol 31: 3549-3556. [Crossref]
12. Oyekunle AA, Kröger N, Zabelina T, Ayuk F, Schieder H, et al. (2006) Allogeneic stem-cell transplantation in patients with refractory acute leukemia: a long-term followup. Bone Marrow Transplant 37: 45-50. [Crossref]

13. Shi-Xia X, Xian-Hua T, Hai-Qin X, Bo F, Xiang-Feng T (2010) Total body irradiation plus cyclophosphamide versus busulfan with cyclophosphamide as conditioning regimen for patients with leukemia undergoing allogeneic stem cell transplantation: a meta-analysis. Leuk Lymphoma 51: 50-60. [Crossref]

14. Sisler IY, Koehler E, Koyama T, Domm JA, Ryan R (2009) Impact of conditioning regimen in allogenic hematopoietic stem cell transplantation for children with acute myelogenous leukemia beyond first complete remission: a pediatric blood and marrow transplant consortium (PBMTC) study. Biol Bone Marrow Transplant 15: 1620-1627. [Crossref]

15. Uberti JP, Agovi MA, Tarima S, Haagenson M, Gandham S, et al. (2011) Comparative analysis of BU and $\mathrm{CY}$ versus $\mathrm{CY}$ and $\mathrm{TBI}$ in full intensity unrelated marrow donor transplantation for AML, CML and myelodysplasia. Bone Marrow Transplant 46: 34 43. [Crossref]

16. Park J, Choi EK, Kin JH, Lee SW, Song SY, et al. (2014) Effects of total body irradiation-based conditioning on allogeneic stem cell transplantation for pediatric acute leukemia: a single-institution study. Radiat Oncol 32: 198-207. [Crossref]

17. Liu H, Zhai X, Song Z, Sun J, Xiao Y, et al. (2013) Busulfan plus fludarabine as a myeloablative conditioning regimen compared with busulfan plus cyclophosphamide for acute myeloid leukemia in first complete remission undergoing allogeneic hematopoietic stem cell transplantation: a prospective and multicenter study. J Hemat Oncol 6: 15. [Crossref]

Copyright: $\odot 2018$ West MN. This is an open-access article distributed under the terms of the Creative Commons Attribution License, which permits unrestricted use, distribution, and reproduction in any medium, provided the original author and source are credited. 